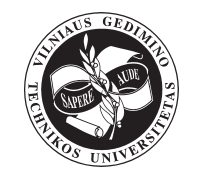

\title{
SAFETY IMPROVEMENTS BY ELIMINATING HAZARDOUS COMBINATIONS
}

\author{
Yossi Hadad ${ }^{1}$, Zohar Laslo ${ }^{2}$ and Avner Ben-Yair ${ }^{3 *}$ \\ Dept of Industrial Engineering and Management, Sami Shamoon College of Engineering, \\ P. O. Box 950, Beer-Sheva 84100, Israel

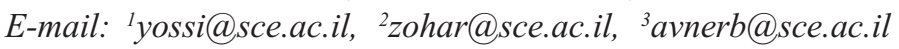

Received 5 January 2007; accepted 7 June 2007

\begin{abstract}
In this paper we suggest the hazardous combinations method to facilitate safety improvements in technical and technological systems by eliminating combinations of major risk factors. The method is capable to significantly improve the safety level in systems as compared to a common situation when only the root causes of accidents were analysed (usually with unsatisfactory results), or where the usual procedures proved to be ineffective due to organisational, technological or financial constraints. In many cases the management decides to implement costly safety measures which have eventually only a minor effect, if at all, on preventing severe accidents. By focusing on prevention of not all recognised primary risk factors but only their hazardous combinations, both human lives and significant financial resources may be saved.
\end{abstract}

Keywords: safety improvements, risk factors, accidents, root causes, hazardous combinations.

\section{Introduction}

To successfully manage a complex technical or technological system which comprises risk factors (hazards) threatening to cause health and safety-at-work events (accidents), the connection between those factors has to be studied, as well as the understanding of how each factor might affect the performance. These are essential conditions, although not always sufficient, for a systematic procedure for performance improvement. Our ability to define the factors affecting the system performance is in many cases very restricted. The reason for the non-consistency to adequately describe the system behaviour lies in noise factors. Our inability to predict the system performance, even after having defined most of the relevant factors, reveals our insufficient knowledge or misunderstanding of the effects of interactions between each factor, if not our total unawareness of their mere existence. For cases where no splitting of combined factors was made, the effect of a single factor expresses, mainly, an average value that has no special significance. The existence of interactions, and the combination between the factors affect the unique influence of each factor and often also their direction (positive or negative).

\footnotetext{
* Corresponding author
}

Also, for safety improvements, as with system improvements, we cannot rely only on a statistical base derived from the number of accidents. As shown by Stewart [1], in most cases it is insufficient just to identify the root cause of the accidents. Therefore we must identify other factors during the whole period that the system was operating (Withers) [2]. The cases where an accident is caused by a single hazard are rare indeed. Usually, accidents result from interactions between many hazards, amongst them, risk factors are simply unidentified. As outlined by Kletz [3], non-dominant risk factors and interactions between hazards do not receive the attention they deserve - not during training and not in most safety procedures.

The "hazardous combinations" method will undoubtedly improve the safety level for systems where only root causes of accidents have been analysed so far (mostly with unsatisfactory results), or where the usual procedures were found to be ineffective due to organisational, technological or financial constraints (as outlined by Peters et al. [4]).

The paper is organised as follows: Section 2 describes the $5 \mathrm{M}$ model and Section 3 presents the expansion of the analysis to include secondary factors for safety. Section 4 analyses the hazard combinations method in general, while Section 5 provides for a comprehensive example of its implementation. Section 6 presents the summary and list of conclusions. 


\section{Major group factors in safety events - the $5 \mathrm{M}$ model}

The $5 \mathrm{M}$ model described by the Center for Chemical Process Safety [5] is being the currently agreed method for evaluating risk factors at six large factories in Israel with similar characteristics. The factories were selected at random and, for obvious reasons, their names are not identified. Every factory employs more than 50 workers and is obligated by law to employ a safety manager. The safety managers of each factory examined all the safety events that occurred between 1998 and 2001 (the data for these 4 years was collected from plant management reports on identical forms). The safety managers reported the incidents without any reference to their gravity. They also noted the root cause for each incident. The risk factors singled out according to model $5 \mathrm{M}$ are:

Man - human factor;

Media - environment factors (including mainte-nance);

Mission - mission factors;

Machine - technical factors (technical failures, mechanical or material failures), and Management - managerial factors.

After analysing the safety events in 6 factories, the following conclusions were made:

1. Human factors are the dominant root cause for industrial accidents.

2. Machine, mission and management groups accordingly are highly significant factors in safety events.

3. Environmental factors have only a limited effect on safety events in the 6 factories that were examined see Table 1 for distribution of the percentage of safety events caused by each group factor.

Common characteristics for all 6 factories examined can explain this distribution frequency of the group factors defined as the root cause for the safety events (for more about industrial risk assessment see Pitblado et al [6]).

\section{Man - the human factor}

The employees are young workers in their twenties or early thirties, many with a high motivation (sometimes too high) and a high self-esteem; the average experience of these workers from the time they finished their training, was about one year. The cause of accidents related to the human factor are:

violation of work procedures and regulations; lack of basic knowledge due to poor experience; mistakes due to misunderstanding, evaluation or thinking process, negligence; operational error; inadequate performance.

\section{Machine - technical factors}

Large and complicated machines having a relatively high tendency to fail.

\section{Mission - mission factors}

Operation of the machines is not routine (various tasks performed at irregular frequencies requiring physical contact with the machine and having high quality demands and a tight schedule).

\section{Management - managerial factors}

Work procedures are evolved by maintenance and operations personnel according to their requirements with a goal to achieve a minimum downtime of the plant. Safety personnel are involved only in safety procedures and failure correction techniques. Managerial outlook and the development of work procedures are based on the employment of young workers who frequently change jobs, and on permanent workers specialising in a narrow field of work. New workers are given only basic training to fulfil the requirements of the specific job. Continuous educational training is planned for the new workers over a period of time. The main emphasis is on providing practical experience by the more experienced personnel.

\section{Media - environmental factors}

Established workplaces are well lit up and signposted. However, permanent noise factors in the plants (sometimes reaching the upper allowed limits) may cause mental stresses and difficulties in communication between workers; heat loads; insufficient ventilation; crowdedness, on the one hand, and separation from other workers, on the other (a worker may find himself between large high machines and loose eye contact with other workers) - as mentioned also by Cooper [7] - may also contribute to propagating safety events.

\section{Expansion of the analysis to include secondary factors for safety}

It can be well-recognised that root cause analysis of safety events has only a limited power to provide system safety improvements. Indeed, the composition of the working group is mostly given and cannot be altered; the training period for the workers cannot be substantially increased; the basic technology cannot be changed since this is usually the "heart" of the plant (minor superficial changes can be made but their contribution to increasing the safety of the plant is minimal); the factory has to fulfil its production program defined by the management, and there is no practical way to reduce the pressure on the plant or its workers; customer satisfaction is only ensured if the product is delivered on time; also, managerial factors, such as the employees background, cannot be changed significantly; environmental factors, that have only a minor effect on safety, are dependent on technology and its advance - when achievable - and usually require very high investments.

An analysis of the root causes responsible for safety events usually leads to a dead end. In order to resolve this problem, we looked for ways to improve safety and hygiene by utilising combinations of these factors. On the form filled out by the safety manager during 4 years of collecting the data, only the root cause for the event was singled out by 14 experts from the 6 factories analysed. According to their evaluation, each risk factor (primary or secondary) was capable of causing the safety event.

The complete set of data over the 4 year period was presented to the experts excluding the root cause of the safety event. 
14 experts evaluated the data for all the factors that they believed were responsible for the safety events presented in Table.

Experts' evaluation of risk factors causing safety events

\begin{tabular}{|c|c|c|c|c|c|}
\hline Expert & Man, $\%$ & $\begin{array}{c}\text { Ma- } \\
\text { chine, } \%\end{array}$ & $\begin{array}{c}\text { Mission, } \\
\%\end{array}$ & $\begin{array}{c}\text { Mana- } \\
\text { gement, } \%\end{array}$ & Media, $\%$ \\
\hline 1 & $80 \%$ & $57 \%$ & $80 \%$ & $94 \%$ & $8 \%$ \\
\hline 2 & $85 \%$ & $40 \%$ & $40 \%$ & $90 \%$ & $28 \%$ \\
\hline 3 & $90 \%$ & $35 \%$ & $12 \%$ & $89 \%$ & $38 \%$ \\
\hline 4 & $84 \%$ & $49 \%$ & $80 \%$ & $90 \%$ & $11 \%$ \\
\hline 5 & $95 \%$ & $10 \%$ & $37 \%$ & $78 \%$ & $65 \%$ \\
\hline 6 & $100 \%$ & $5 \%$ & $24 \%$ & $75 \%$ & $76 \%$ \\
\hline 7 & $93 \%$ & $18 \%$ & $39 \%$ & $88 \%$ & $44 \%$ \\
\hline 8 & $96 \%$ & $10 \%$ & $30 \%$ & $75 \%$ & $70 \%$ \\
\hline 9 & $95 \%$ & $17 \%$ & $25 \%$ & $80 \%$ & $60 \%$ \\
\hline 10 & $75 \%$ & $65 \%$ & $66 \%$ & $95 \%$ & $7 \%$ \\
\hline 11 & $75 \%$ & $70 \%$ & $35 \%$ & $100 \%$ & $5 \%$ \\
\hline 12 & $94 \%$ & $18 \%$ & $4 \%$ & $87 \%$ & $59 \%$ \\
\hline 13 & $91 \%$ & $30 \%$ & $36 \%$ & $88 \%$ & $40 \%$ \\
\hline 14 & $83 \%$ & $50 \%$ & $84 \%$ & $90 \%$ & $9 \%$ \\
\hline Average & $88 \%$ & $37 \%$ & $42 \%$ & $87 \%$ & $37 \%$ \\
\hline
\end{tabular}

As the experts were only given a description of the safety events and not allowed to investigate them, sometimes their evaluation indicated less involvement in risk factors than the hazards declared by the safety managers. For the same reason, we found that the dispersion of data for each hazard was relatively large. Therefore, in our survey, we did not rely on this study for identifying the combinations of hazards. We used this survey only for the quantitative evaluation of risk factors causing safety events.

By the experts evaluation, it can be concluded that the risk factors were involved in safety events on an average 3 times more than the number of events analysed (the total of the average involvement of risk factors in safety events: $88 \%+37 \%+42 \%+87 \%+37 \%=291 \%$, relative to $100 \%$ of the events). In other words, in every safety event, for every root cause in one group, on average, there are another 2 factors from two different group factors involved in a safety event.

If we agree with the ruling made by the safety managers that the relative share of the group factors reflects both major and minor causes for safety events, one may reach the following conclusions:

- Human factor: appears in $64 \%$ of the events as the root cause and in $24 \%$ as a secondary factor - total $88 \%$.

- Technical factor: appears in $11 \%$ of the events as the root cause and in $26 \%$ as a secondary factor total $37 \%$.

- Mission factor: appears in $13 \%$ of the events as the root cause and in $29 \%$ as a secondary factor - total $42 \%$.

- Managerial factor: appears in $8 \%$ of the events as the root cause and in $79 \%$ as a secondary factor total $87 \%$.

- Environmental factor: appears in $4 \%$ of the events as the root cause and in $33 \%$ as a secondary factor - total $37 \%$.

\section{Hazardous combinations method}

The group of experts has recognized that a single risk factor may have a different effect, if at all, on each accident when other hazards are involved.

We can identify, empirically, a "hazard combination" by examining the frequency of its appearance in the accidents analysed. Consequently, we suggest an alternative to the traditional analysis where only the root cause of the accident is investigated. We call this procedure the hazard combinations method.

If a complex technical experiment is performed where no work procedures have been written (the managerial factor), having a tight schedule (the mission factor), in a place with restricted eye contact with the rest of the workers (the environmental factor), involving dilapidated equipment and hazardous materials (the technical factor), by inexperienced workers with excessive self-confidence and motivation (the human factor) - this would be of course the perfect recipe for a total disaster (see also the classic study by Trento [8]).

In order to identify the hazard combinations for the risk factors resulting in accidents, the specific hazards from each group factor must be specified: $M_{i}$, from 5 group factors defined according to the model $5 \mathrm{M}$. Each group factor includes $n_{i}$ risk factors. We can conclude from the total list of $n$ factors

$$
n=n_{1}+n_{2}+n_{3}+n_{4}+n_{5} .
$$

In addition to the $n$ factors contributing to safety events that appear in the list, we must identify from all possible combinations $\left(2^{n}-(1+n)\right)$ in number, combinations estimated that are liable to cause the safety events.

An example of these combinations $(k=4)$ may be described as follows:

1. Inexperienced worker.

2. Tight schedule.

3. Unfamiliar mission.

4. Dilapidated equipment.

Combining all these factors together may be especially dangerous. It is possible that, for example, just replacing the inexperienced worker by a more experienced one $(k=3)$, and leaving the remaining factors, may substantially reduce the overall risk level. However, when the time is limited and with the same hazard combination of $k=3$, the same risk level is maintained. If we continue the examination, we may conclude that the risk level will not be reduced even if the time is extended, and changing the hazard combination $(k=2)$ is therefore required. Consequently, any combination of an inexperienced worker under unfamiliar conditions can be described as a hazardous combination. From this, we can conclude that in order to reduce the risk level, we must not allow an inexperienced employee 
to work in unfamiliar conditions. The experience of a worker might enable him to overcome the difficulties associated with an unknown operation, while, on the other hand, even an inexperienced worker may overcome the dangers involved in a routine operation.

A research approach to this problem obligates us not to interfere in the process of empirical data collection required to estimate the risk level of each combination. Neutrality enables us to estimate the risk levels for all combinations from the second degree (two-way interaction) till the $n$-th order ( $n$-way interaction), thus trying to prevent their appearance during the operation of the plant. The frequency, and the large number of factors involved in safety events for the six factories examined, lead to the conclusion that safety improvements should be frozen for several years. As we are talking about health hazards or even danger to the lives of the employees, we are forced to adopt an approach whereby there is a degree of interference in the factors involved after we have singled out the hazard combinations (following observations or evaluation by experts). The intervention can be justified only when, in retrospect, it was impossible to know whether each factor could be treated separately for every combination of the possible hazards.

We propose a method of continuous safety improvement whereby hazard combinations are eliminated. It is based on the following stages:

Stage 1. Primary identification of hazardous combinations of the $k$-th order. Since the number of possible combinations might be extremely large (for $n=20$, there exist $1,115,115$ possible combinations), it is recommended to examine and estimate as a primary identification, the combination in the 4-th order $(k=4)$. The number of combina-

tions is now reduced to a maximum of $\left(\begin{array}{l}n \\ k\end{array}\right)=\frac{n !}{(n-k) ! k !}$

(for more details see Walpole and Myers [9]). For $n=20$ and $k=4$ we now have to examine and evaluate up to "only" 4,845 combinations - which presents a significant reduction, although still a lot of work to carry out.

Stage 2. Disassembly of combinations that will enable us to concentrate on groups of combinations and, consequently, considerably reduce the final number to be examined. For $n=20$ and $k=4$ only hundreds or combinations remain to be examined.

In a system, $n$ primary danger factors were identified (for example: inexperienced worker - A; no eye connection $-\mathrm{B}$ : noise $-\mathrm{C}$; unfamiliar assignment $-\mathrm{D}$; tight schedule $-\mathrm{E}$; excessively motivated employees $-\mathrm{F}$ : dilapidated equipment $-\mathrm{G}$; dangerous materials $-\mathrm{H}$ etc).

When the identification of every hazard combination of the $k$-th order is complete, they must be disassembled to $k$ combinations of the $(k-1)$-th order, and then subject to identification of hazard combinations amongst them. Identification of hazard combinations of the ( $k$-1)-th order enables us to erase from the list of hazard combinations of the $k$-th order, that need to be examined, all sub-combinations of the ( $k$-1)-th order. This disassembly process may be continued to include all danger combinations of the $(k-1)$-th order and so on, till the second order is reached. For example, see Fig describing the algorithm flow diagram defining hazard combinations on the basis of identification of all hazard combinations of the $k$-th order. It goes without saying that when $k$ and $n$ increase, the possibility of time saving increases significantly.

Stage 3. Prevention of the creation of hazard combinations. Implementation of instructions, wherever possible, to eliminate hazard combinations that have been identified.

Stage 4. Examination of the frequency effect on safety events. An empirical examination of safety events taken from field data was made relating to the effect of their frequency and other factors. The examination requires collection of data on all the factors on each safety event as a primary or secondary factor according to the check list where all the details of the event are listed. It is important to localize additional risk factors (if such exist) and add them to the list.

Stage 5. Follow-up on additional combinations. Occurrence frequency and the effect of additional combinations after adding them to the list of hazard combinations with an explanation on how to prevent, where possible, their appearance, is carried out.

After defining the additional factors, actions described on Stages 1-3 must be repeated.

Stage 6. Follow-up on the frequency of safety events relative to the time when the events took place.

\section{Implementation example}

To demonstrate practical implementation of the above theoretical suggestions, including identification of risk factors and hazard combinations, consider planting in a flower pot.

In order to develop, a plant in a flower pot requires, amongst other things, sunlight and water. Sunlight and water are considered major factors affecting its development. On the other hand, excess sunlight may result in its drying up and excess water may result in its decay. Consequently, sunlight and water may also be considered as major risk factors to the life of the plant.

Suppose the planting was carried out in spring - unstable climatic conditions with intermittent rain and sunshine. The plant may be placed in 4 possible positions on the balcony of the house:

Area I: In the shade and partially covered against rain.

Area II: In the shade and open to rain.

Area III: Exposed to the sun and partially covered against rain.

Area IV: Exposed to the sun and open to rain.

Consider the following relationships according to primary risk factors, as well as their certain combinations.

If we want to protect the plant from two major risk factors, we would choose Area I where the plant is totally protected from all primary risk factors (overexposure to sun and excess of water). Theoretically, the combination of a shaded area with moderate water supply should be beneficial for the plant's development. However, there is a hitch 


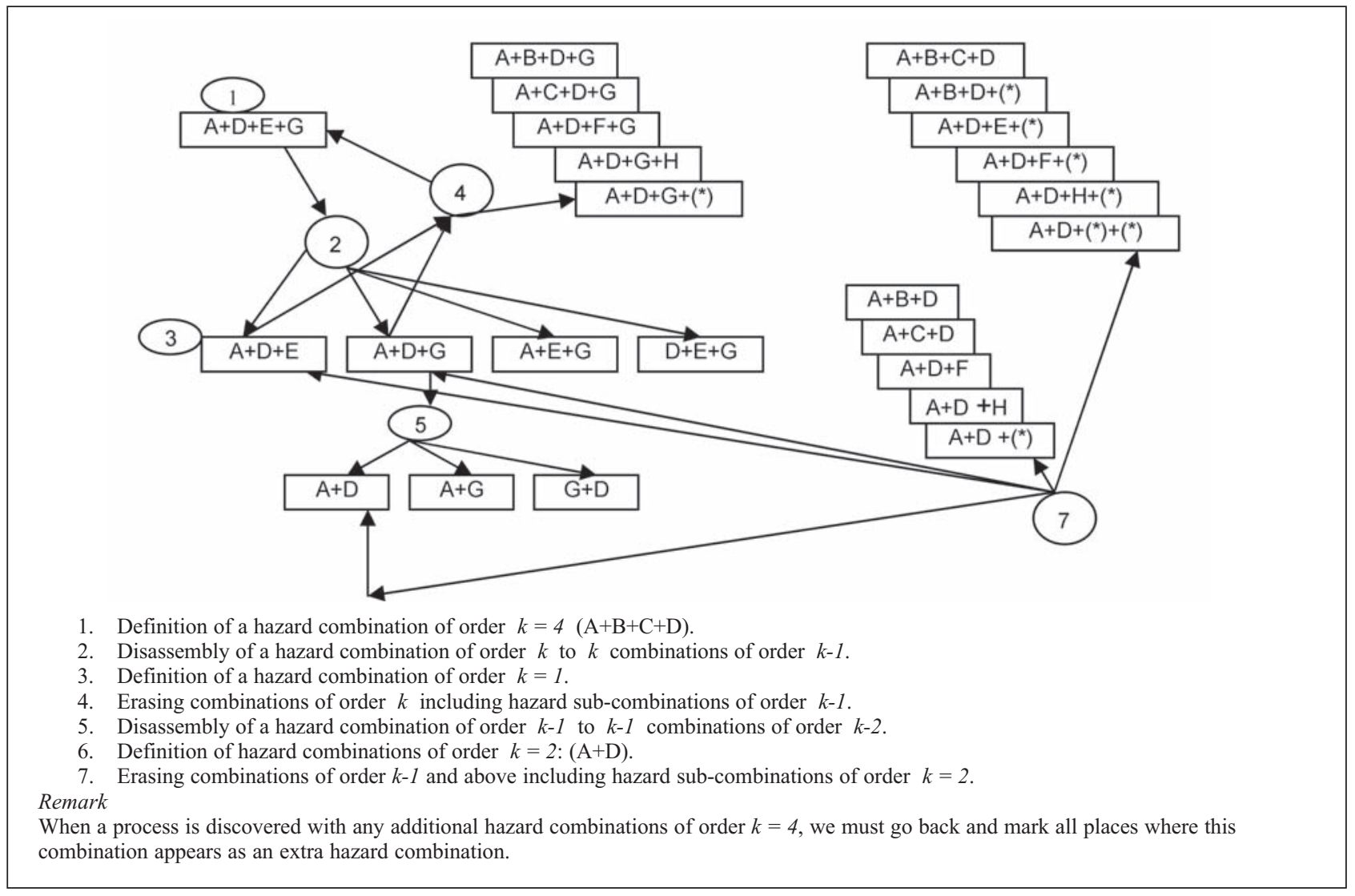

Disassembly process of a suspicious combination to combinations of a lower order and their data

somewhere: under these conditions, the plant does not grow well if at all.

Let us consider therefore hazard combinations of the risk factors.

It is clear that in order to develop the plant, we must consider placing it in one of the three remaining areas.

Area II is a hazard combination since excess water without evaporation will result in the plant's decay. Area III is also a danger combination: excessive evaporation of the water without constant watering will certainly cause the plant to dry out and die.

Surprisingly, placing the plant in Area IV, where it is exposed to both major risk factors, cannot be regarded as a hazard combination, because the high water supply is balanced by a high evaporation rate. Consequently, there is no danger of decay or drying out of the plant. In this case, as in many other instances, major risk factors are also factors providing success - not only that their certain combinations prove to be not hazardous, but they even may turn out to be the most effective ones.

\section{Conclusions}

The method for safety improvements in systems based on elimination of hazard combinations allows us to identify unique conditions that might, in time, lead to a safety event. A concentrated effort to investigate these unique con- ditions is far more effective than dealing separately with the risk factors themselves.

The hazards causing accidents that were examined and found in the scenario, each factor separately or in any combination, effect the probability of an accident occurring. The remaining scenarios, those without hazard combinations, are usually considered safe.

The significance of this procedure boils down to the following:

1. Relative ease of identification of those scenarios requiring deeper examination.

2. Only scenarios providing hazard combinations are examined in depth.

Dealing with a combination of factors where accidents can be prevented by choosing an alternative way to perform a task, is more practical than treating straightforwardly primary risk factors (the latter requires usually technical or managerial changes that deter the high level management).

A computer program has been written capable of providing the decision makers, in the first stage, with a managerial tool to identify a primary group of hazard combinations by empirical analysis of results from the past (if any). In the second stage, it is designed to single out, in advance, possible hazards. According to the evaluation by experts, this procedure enables us to quickly and economically analyse the safety events by reducing the number of hazard combinations to be examined. In the third stage, the com- 
puter program enables us, by combining the first two stages, to update the list of hazard combinations even after identification of new major hazardous combinations.

\section{Acknowledgements}

The authors acknowledge the contribution of our student Mr Mordekhai Finish who participated in the hazardous combinations research.

The authors express their sincere gratitude to Mr Alan Becker for important remarks and suggestions which contributed greatly to the paper's quality.

\section{References}

1. STEWART, S. Air Disasters. Ian Allan Publishers, London, 1986.

2. WITHERS, J. Major Industrial Hazards. Gower, Aldershot, UK, 1988.
3. KLETZ, T. A. Learning from Accidents. $2^{\text {nd }}$ ed, ButterworthHeinemann, Oxford, UK, 1994.

4. PETERS, O. H., and MEYNA, A. Handbuch der Sicherheitstechnik I. Carl Hanser Verlag, München, 1985 (in German).

5. Center for Chemical Process Safety, Guidelines for Investigating Chemical Process Incidents. American Institute of Chemical Engineers, New York, 1993.

6. PITBLADO, R., and TURNEY, R. D. (eds.). Risk Assessment in the Process Industries. $2^{\text {nd }}$ ed, Chapter 3, Institution of Chemical Engineers, Rugby, UK, 1996.

7. COOPER, M. G. Risk: Man-Made Hazards to Man Clarendon Press, Oxford, UK, 1985.

8. TRENTO, J. J. Prescription for Disaster. Crown Publishing Co, New York, 1987.

9. WALPOLE, R. E., and MYERS, R. H. Probability and Statistics for Engineers and Scientists. $4^{\text {th }}$ ed, Macmillan Publishing Company, 1990.

\section{SAUGOS GERINIMAS ŠALINANT PAVOJINGŲJŲ VEIKSNIŲ DERINIUS}

\section{Y. Hadad, Z. Laslo and A. Ben-Yair}

Santrauka

Straipsnyje siūlomas pavojingujų derinių metodas, kuris padeda pagerinti techninių ir technologinių sistemų saugą, šalinant didžiausios rizikos veiksnių derinius. Jis gali būti taikomas, kai visuotinai paplitusi priežasčių analizè neduoda teigiamų rezultatų arba kai ịprastinès procedūros nèra efektyvios dẻl organizacinių, technologinių arba finansinių apribojimų. Daugeliu atvejų diegiamos brangios saugos priemonès, kurios duoda nedidelį efektą, galbūt užkardo stambias avarijas. Sutelkiant dėmesį ne į visus i̇manomus rizikos veiksnius, bet tik i jų pavojinguosius derinius, gali būti išgelbètos ir žmonių gyvybẻs, ir sutaupyta lèšu.

Reikšminiai žodžiai: saugos gerinimas, rizikos veiksniai, avarijos, priežastys, pavojingieji deriniai.

Yossi HADAD. Doctor. Department of Industrial Engineering and Management. Sami Shamoon College of Engineering. First Degree in Industrial Engineering and Management, Ben-Gurion University of the Negev, Beer-Sheva, Israel (1984). Master of Science (1995). Doctor (2000). Author of about 40 scientific articles.

Research interests: Data Envelopment Analysis, Analytical Hierarchical Process, ranking methods, work study, production planning, scheduling and control.

Zohar LASLO. Doctor, Associate Professor. Dean. Sami Shamoon College of Engineering. First Degree in Industrial Engineering and Management, The Technion, Israel Institute of Technology, Haifa, Israel (1967). Master of Science (1973). Doctor, Ben-Gurion University of the Negev, Beer-Sheva, Israel (1995). Post Doctoral Research Fellow, Tel-Aviv University, Tel-Aviv, Israel (1997). Author of about 40 scientific articles.

Research interests: performance of organizational structures, planning, scheduling and control under time-cost uncertainty, implementation of networks in manufac-turing systems and project management, technological education.

Avner BEN-YAIR. Doctor. Department of Industrial Engineering and Management. Sami Shamoon College of Engineering. First Degree in Mechanical Engineering, Polygraphic Institute, Moscow, USSR (1985). Master of Science, Ben-Gurion University of the Negev, Beer-Sheva, Israel (2001). Doctor (2004). Author of about 40 scientific articles.

Research interests: system performance and effectiveness, reliability and failure analysis, fault tree analysis, trade-off optimization models for organization systems, risk analysis and contingency planning, maintainability and hazard analysis techniques, economic aspects of safety, production planning, scheduling and control, strategic management, network models structure and project scheduling, cost optimization and PERT-COST models. 